\title{
Telemedicine in the management of chronic pain: a cost analysis study
}

\section{La télémédecine pour la prise en charge de la douleur chronique: une étude d'analyse des coûts}

\author{
Antoine Pronovost, MD · Philip Peng, MBBS • \\ Ralph Kern, MD
}

Received: 29 October 2008/Revised: 8 May 2009/Accepted: 13 May 2009/Published online: 30 May 2009

(C) Canadian Anesthesiologists' Society 2009

\begin{abstract}
Purpose Telemedicine provides patients with easy and remote access to consultant expertise irrespective of geographic location. In a randomized controlled trial, this study has applied a rigorous costing methodology to the use of telemedicine in chronic pain management.

Methods We performed a randomized two-period crossover trial comparing in-person (IP) consultation with telemedicine (TM) consultation in the management of chronic pain. Over an 18-month period, 26 patients each completed two diaries capturing their direct and indirect travel costs, daily pain scores, and satisfaction with physician consultation. Costing models were developed to account for direct, indirect, fixed, and variable costs in order to perform break-even analyses. Sensitivity analysis was performed over a broad range of assumptions.

Results Direct patient costs were significantly lower in the TM group than in the IP group, with median cost and interquartile range $\$ 133$ (28-377) vs \$443 (292-1075),
\end{abstract}

\footnotetext{
A. Pronovost, MD

Department of Anesthesia, St. Michael's Hospital,

Toronto, ON, Canada

P. Peng, MBBS ( $\square)$

Department of Anesthesia, University Health Network,

McL 2-405, TWH, 399 Bathurst Street, Toronto,

ON M5T 2S8, Canada

e-mail: philip.peng@uhn.on.ca

P. Peng, MBBS

Wasser Pain Management Center, Mount Sinai Hospital,

Toronto, ON, Canada

R. Kern, MD

Department of Medicine, Division of Neurology,

Mount Sinai Hospital, Toronto, ON, Canada
}

respectively $(P=0.001)$. More patients were highly satisfied with the TM consultation than with the IP consultation (56 and 24\%, respectively; $P<0.05$ ). Breakeven annual patient volume was estimated at 57 patients. A two-way sensitivity analysis controlling for annual patient volume and round-trip distance indicated that TM remains cost-effective at volumes $>50$ patients/year or at round-trip distances $>200 \mathrm{~km}$.

Conclusion Telemedicine is cost-effective over a broad range of assumptions, including annual patient volumes, travel distance, fuel costs, amortization, and discount rates. This study provides data from a real-world setting to determine relevant thresholds and targets for establishing a TM program for patients who are undergoing chronic pain therapy.

\section{Résumé}

Objectif La télémédecine procure aux patients un accès facile et à distance à l'expertise d'un consultant, indépendamment de leur emplacement géographique. Bien que cette approche ait été utilisée dans d'autres domaines de la médecine, il n'existe à ce jour aucune étude ayant appliqué une méthodologie de tarification rigoureuse dans le cadre d'une étude randomisée contrôlée portant sur l'usage de la telémédecine pour la prise en charge de la douleur chronique. Méthode Nous avons réalisé une étude randomisée croisée en deux périodes comparant les consultations En Personne (EP) aux consultations de Télémédecine (TM) pour la prise en charge de la douleur chronique. Au cours d'une période de 18 mois, 26 patients ont rempli deux journaux de bord en inscrivant les coûts directs et indirects liés aux déplacements, ainsi que leurs scores de douleur quotidiens et la satisfaction éprouvée par rapport à la consultation avec le médecin. Des modèles de couts ont été créés afin de tenir compte des coûts directs, indirects, fixes 
et variables, ce qui a permis de réaliser des analyses de rentabilité. L'analyse de sensibilité a été réalisée sur une vaste gamme d'hypothèses.

Résultats Les coûts directs pour les patients étaient significativement plus bas dans le groupe TM, avec un coût médian et un intervalle interquartile de 133 \$ (28-377) vs. $443 \$$ (292-1075) dans les groupes TM et EP, respectivement $(p=0,001)$. Un nombre plus élevé de patients était très satisfait de la consultation en Telémédecine $156 \%$ et $24 \%$ dans les groupes TM et EP, respectivement; $p<0,05)$. Le nombre de patients pour lequel les coûts s'équivalent a été estimé à 57 patients par année. Une analyse de sensibilité à deux critères contrôlant le volume annuel de patients et la distance d'un aller-retour a permis de déterminer que la TM demeure rentable même à des volumes plus importants que 50 patients/année, ou à des distances d'aller-retour de plus de $200 \mathrm{~km}$.

Conclusion La télémédecine est une approche rentable si l'on tient compte d'hypothèses variées portant sur les volumes annuels de patients, la distance de déplacement, le coût de l'essence, l'amortissement et les rabais. Cette étude fournit des données prises dans un contexte réel qui permettent de déterminer les seuils et cibles pertinents si l'on souhaite établir un programme de télémédecine destinéaux patients suivant un traitement pour leur douleur chronique.

Telemedicine (TM) refers to using information and communications technology to provide health care services to individuals who are some distance from the health care provider. ${ }^{1}$ Telemedicine has been used successfully in a few specialties, such as psychiatry and cardiology, for counselling and monitoring of treatment response. ${ }^{2,3}$ However, $\mathrm{TM}$ is relatively new to other medical disciplines. It relies on high-speed, high-bandwidth telecommunication systems that allow two-way real-time clinical consultations over an audio-video link augmented by other modalities, such as an electronic stethoscope and a high-resolution image viewer.

Of the approximately one in five adult Canadians who experience chronic pain, ${ }^{4} 70 \%$ report moderate to severe intensity of pain and discomfort. ${ }^{5}$ This group is most likely to benefit from multi-disciplinary pain management, ${ }^{6,7}$ that includes taking prescription medications for pain, and frequent follow-up. ${ }^{8}$ In Canada, a mismatch exists between population distribution and Multidisciplinary Pain Treatment Facilities (MPTFs). Approximately $20 \%$ of the population lives in rural areas (population $<10,000$ ), but only $2 \%$ of MPTFs are located in these areas. ${ }^{9}$ Therefore, many patients travel long distances to their nearest treatment facility. As chronic pain is commonly associated with significant disability, particularly for patients with musculoskeletal disease, ${ }^{10}$ acute worsening of daily pain scores, due to extensive travel, is a particular concern. Feasibly, TM could deliver high-quality expert-driven chronic pain management irrespective of patient geographical location. Therefore, we hypothesized that TM consultations could result in decreased cost and increased patient satisfaction due to shorter travel time, less reliance on caregivers to attend clinic follow-up, reduced patient suffering, and increased productivity.

Previous studies of TM in the management of chronic pain focused on feasibility assessment ${ }^{11,12}$ without providing quantitative estimates and analysis of costs and benefits. A small pilot study suggested that chronic pain patients prefer TM to standard clinic assessment because of significant savings in cost and time. ${ }^{13}$ This study was undertaken to evaluate the costs and clinical outcomes in patients receiving both TM and traditional in-person (IP) clinic visits for chronic pain management.

\section{Methods}

We performed a randomized controlled two-period crossover trial of chronic pain patients returning for follow-up assessment. After approval from the Ethics Review Board of Mount Sinai Hospital, University of Toronto, consenting patients were randomized for either IP or TM for the next visit, followed by a second crossover visit via TM or IP, respectively. Three physicians at a single site took part in the care of the study patients.

Inclusion criteria were: chronic pain (more than 6 months) without any demonstrable correctable pathology, stable chronic pain with no anticipated need for a physical exam on follow-up, a travel distance $>100 \mathrm{~km}$, and age $>18$ years. Exclusion criteria included significant cognitive or communication impairment rendering TM impossible or unsafe and a recent history of substance abuse.

After obtaining consent, the patients were randomized by a study coordinator according to a computer-generated list. Allocation was not concealed. Telemedicine consultations were scheduled by the pain clinic secretary through the Ontario Telemedicine Network (an established provincial government program) within regular clinic hours. Patients were asked to follow their usual travel arrangements for their IP visit, and their preferred method for the TM visit. Each patient prospectively completed a diary capturing travel costs, time required for the IP or TM visit, daily pain scores, and subsequent health care costs and medical visits for 3 months. Each patient was asked to chart his/her average daily numeric pain score on a standard 10-point scale ( 0 being no pain, and 10 being the worst pain). On average, crossover occurred within three months (range 2-4), at which point the first diary was collected and a second diary was distributed.

Commercial broadband videoconferencing equipment complying with international standards and supporting 
virtual private network security was used for the TM consultations. The equipment in the patient site included a monitor, speakers, and a light source (AMD-300, AMD Telemedicine Inc, Lowell, MA, USA) connected to two multi-purpose analogue general examination cameras (AMD-2500s, AMD Telemedicine Inc, Lowell, MA) with power zoom, auto focus, and freeze frame capture. The equipment in the consultant site, which was located in a regular patient examining room, included the Tandberg 880 videoconference unit (Tandberg, New York, NY, USA) mounted on a mobile stand, a viewing monitor, camera, digital stethoscope, and a desktop computer.

The primary outcome was cost. Patient costs were captured prospectively by a patient diary. Direct costs to patients included travel expense, such as mileage, and lodging or meals, when necessary. Indirect costs to patients included lost productivity for currently employed patients and the costs recorded by patients for medications and uninsured health visits (including allied health visits, such as chiropractic care and physiotherapy). Attendant costs were also captured by the patient diary, i.e., when patients required either a family member or friend to assist in travel to and from the appointment. Attendant costs included direct costs of travel, such as meals, and indirect costs, such as lost productivity if employed. Institutional costs were ascertained based on administrative data. They included the fixed costs of equipment as well as the variable costs of the program, including personnel salary.

Other outcome measures for both IP and TM visits included satisfaction with the consultation (rated on a 5-point Likert scale), pain scores, and patient's Illness Intrusiveness Rating Scale (IIRS). ${ }^{14}$ The latter is a validated Health Related Quality of Life instrument developed to measure the extent to which a disease or its treatment interferes with activities in important life domains. The IIRS captures ten different domains, including financial situation, work, family relationships, other relationships, health, diet, active and passive recreation, relationship with spouse, sex life, self-expression, and religious expression.

Descriptive statistics are expressed as frequency, mean and standard deviation, with the exception of the costs, which are presented as median and inter-quartile range (IQR). Student's $t$-test was used for comparison of the means, and the costs were analyzed with the Mann-Whitney $U$-test. All data were entered into Excel XP (Microsoft Corporation) and analyzed by intention-to-treat using SPSS (Version 15, Chicago, IL, USA).

The break-even volume of patients was calculated by dividing total fixed costs of TM by marginal savings of TM. This is similar to break-even analysis in a business setting, where it is the result of dividing fixed costs by profit margin. Mileage allowance was then varied in $\$ 0.05$ increments from $\$ 0.15$ to $\$ 0.45$ per $\mathrm{km}$, and marginal savings of TM were recalculated based on each discrete mileage assumption to generate break-even patient volume.

To determine minimal marginal savings to achieve break even, two-way sensitivity analysis of break-even distance and patient volume was generated by dividing the average total annual fixed costs, based on a five-year amortization period, by patient volumes ranging from 50 to 100 per annum. Previous transportation costs were then removed from the existing model, and minimal distance to treatment centre was calculated to determine break-even point based on a mileage allowance of $\$ 0.25$ per $\mathrm{km}$.

Sensitivity to discount rate and amortization was generated by dividing total fixed costs by marginal savings for amortization periods ranging from 1 to 5 years. Thus, fixed costs amortized over a shorter period would yield a higher break-even volume. Future savings were discounted by rates 0,5 , and $10 \%$ (compounded annually), yielding three different sensitivity curves.

Our pilot study previously indicated an average cost savings of $\$ 275$ for the TM group and a standard deviation of $\$ 417 .^{13}$ Accepting a $P$-value of 0.05 and power 0.8 , the sample size would be 20 patients for a difference of $\$ 275$. Factoring in a $25 \%$ attrition rate for events, such as protocol violation and withdrawal from the study, 25 patients were recruited.

\section{Results}

From December 2005 to May 2007, 38 consecutive patients, who met study inclusion criteria, were approached for participation in this study. Eight patients did not return a questionnaire after their first visit, and two patients did not return a questionnaire after their second visit. One patient withdrew consent and a second patient withdrew from the study because the TM was farther from her home than the IP site. Twenty-six patients from 29 to 69 years of age, who were successfully recruited to the study, progressed to return both diaries. Altogether, 52 completed diaries were obtained. Baseline patient demographics are presented in Table 1.

Patient satisfaction, pain scores, and impact on quality of life

Patients were significantly more satisfied with TM consultation compared with IP consultation (Table 2). Fifty-six percent of TM patients were highly satisfied with the TM consultation compared with $24 \%$ of the IP patients. Illness Intrusiveness Rating Scale scores were similar in the two groups (Table 3). Average pain scores for the day of consultation, day after consultation, week of consultation, and two-month follow-up were not significantly different (Table 3). 
Table 1 Baseline demographic data for enrolled patients

\begin{tabular}{ll}
\hline Age & $49(43-60)$ \\
Gender (M:F) & $9: 17$ \\
Number of patients receiving long-term & $20(74)$ \\
$\quad$ disability or pension income (\%) & \\
Average annual salary of currently & $50,000(34,000-$ \\
$\quad$ employed patients (Canadian dollars) & $52,500)$ \\
Number of years with chronic pain & $10(7-17)$ \\
Numeric pain score (minimum =0, & $7(5.6-8.0)$ \\
$\quad$ maximum = 10) on the day of first visit & \\
Distance from MPTF (km) & $478(292-780)$ \\
\hline
\end{tabular}

Data are presented as median and interquartile range (in parentheses) unless specified

MPTF multidisciplinary pain treatment facility

Table 2 Patient satisfaction for both in-person and telehealth visit

\begin{tabular}{lcrlll}
\hline \multicolumn{5}{c}{$\begin{array}{l}\text { 'I am satisfied with the format of this consultation' } \\
\text { Number of response }(\%)\end{array}$} \\
\cline { 2 - 6 } & $\begin{array}{l}\text { *Strongly } \\
\text { agree }\end{array}$ & Agree & Neutral & Disagree & $\begin{array}{l}\text { Strongly } \\
\text { disagree }\end{array}$ \\
\hline Telemedicine & $14(56)$ & $8(32)$ & $3(12)$ & $0(0)$ & $0(0)$ \\
In-person & $6(24)$ & $12(48)$ & $4(16)$ & $2(8)$ & $1(4)$
\end{tabular}

* $P<0.05$ comparing those patients who strongly agree about their satisfaction

Table 3 Pain score and illness intrusiveness rating scale (IIRS) score

\begin{tabular}{lccc}
\hline & TM visit & IP visit & $P$ value \\
\hline Average daily pain score & & & \\
$\quad$ Day of consultation & $6.7(2.5)$ & $6.8(2.6)$ & 0.79 \\
$\quad$ Day after consultation & $6.9(2.9)$ & $6.9(2.6)$ & 0.81 \\
$\quad$ First week & $6.8(2.5)$ & $6.7(2.5)$ & 0.84 \\
IIRS score & $66.7(15.2)$ & $64.1(19.8)$ & 0.61 \\
\hline
\end{tabular}

Data are presented as mean with standard deviations in parentheses

$T M$ telemedicine, $I P$ in-person

\section{Costs analysis}

The cost of patient time was based on each patient's annual income as reported in the diary, assuming 220 annual working days and an 8-hr workday. These were deemed reasonable assumptions based on their conservative value and previous acceptance in other high-quality trials evaluating TM. ${ }^{15}$ Patient travel costs were based on fares, where applicable, although the majority of patients travelled by private vehicle. Cost of travel was estimated at $\$ 0.25$ per $\mathrm{km}$, based on figures from Canada Revenue Agency's 1995 guidelines on allowable expenses. ${ }^{16}$ Total patient costs (sum of travel costs, lost productivity, and medications) were \$442 (IQR 292-1075) and \$133 (IQR
Table 4 Comparison of total patient cost of telemedicine and inperson consultations

\begin{tabular}{lccc}
\hline & $\begin{array}{l}\text { Telemedicine } \\
\text { median (IQR) }\end{array}$ & $\begin{array}{l}\text { In-person } \\
\text { median (IQR) }\end{array}$ & $P$ value \\
\hline $\begin{array}{l}\text { Direct cost of travel } \\
\text { Lost productivity }\end{array}$ & $10(7-16)$ & $197(98-350)$ & $<0.0001$ \\
$\quad$ Patient & $0(0-10)$ & $0(0-64)$ & 0.48 \\
$\quad$ Attendant & $0(0-0)$ & $0(0-190)$ & 0.03 \\
Medical cost & $33(0-309)$ & $31(0-265)$ & 0.95 \\
Total cost & $133(28-377)$ & $442(292-1075)$ & 0.001 \\
\hline
\end{tabular}

All costs are present in Canadian dollars. Data are compared with Mann-Whitney $U$ test

$I Q R$ inter-quartile range

$P<0.05$ as significant

Table 5 Details of institutional fixed and variable costs (in Canadian dollars)

\begin{tabular}{lr}
\hline Institutional step-variable and variable costs $(\$)$ & \\
$\quad$ Annual salary of Telehealth coordinator & \\
$\quad$ (yearly fixed cost) & 3 \\
Booking secretary's variable cost & \\
$\quad$ (increased cost per patient) & 225 \\
Institutional fixed costs (\$) & 20000 \\
Jack & 20000 \\
Modular unit & 350 \\
Setup time (Telehealth coordinator) \\
Secretary training time (based on annual salary)
\end{tabular}

28-377) for IP and TM visits, respectively $(P=0.001)$ (Table 4). Travel allowance accounted for $40 \%$ of total patient costs in the IP group, whereas it represented $6 \%$ of total patient costs in the TM group.

Fixed costs for the institution included those of the modular unit, the setup time for the network, the jack to plug in the modular unit, and secretary training time to learn to book patients on the Ontario Telemedicine Network (Table 5). Variable costs included the extra time required for the secretary to book each patient for their appointment as well as the shared cost of the TM Coordinator to maintain network access. Equipment was depreciated over a 5-year period, at the end of which it was given no residual value.

\section{Break-even point and sensitivity analysis}

Based on a 5-year amortization of equipment costs and a 5\% discount rate, the break-even program participation was 57 patients per annum. At volumes $>57$ patients annually, TM resulted in cost savings from a societal perspective. On an undiscounted basis, mean savings per follow-up assessment 
Sensitivity analysis of mileage allowance on breakeven volume and savings per TM visit

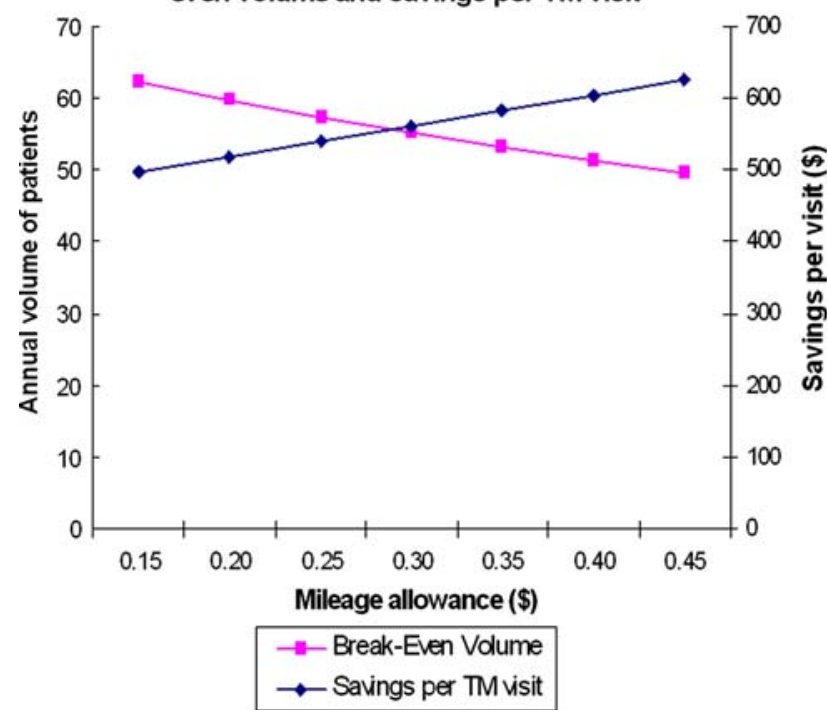

Fig. 1 Mileage allowance sensitivity analysis reveals increased savings and a reduced break-even point with rising fuel costs (based on a 5-year amortization period and a 5\% discount rate)

was estimated at $\$ 544$, and break-even patient volume was further reduced to 52 patients annually.

We chose to perform a sensitivity analysis on the effect of cost-per-kilometre on break-even volume (Fig. 1) because the mileage allowance drove most of the travel costs, resulting in $40 \%$ of costs incurred by patients in the IP arm. In this analysis, even under the most conservative set of assumptions (mileage of $\$ 0.15$ per $\mathrm{km}, 5$-year amortization, and 5\% discount rate), the break-even volume is 62 patients per annum.

\section{Break-even distance}

If the cost of air/rail fare is removed from our model and mileage expense is fixed at $\$ 0.25$ per $\mathrm{km}$, break-even distance varied significantly by the annual volume of patients. At low volumes of 50 patients per annum, the distance rose exponentially to $1174 \mathrm{~km}$. However, this value decreased significantly as volume increased (Fig. 2). Our average, a travel distance of $502 \mathrm{~km}$ would result in a break-even volume of slightly more than 70 patients per annum.

\section{Discounting sensitivity analysis}

Discounting is applied because a dollar earned in the future does not have the same value as a dollar held in the present. This reflects not only interest costs of capital (e.g., mortgage interest) but also risk exposure. For example, changing technology and strategic direction might render equipment obsolete before its anticipated end-of-life cycle. Reviewers

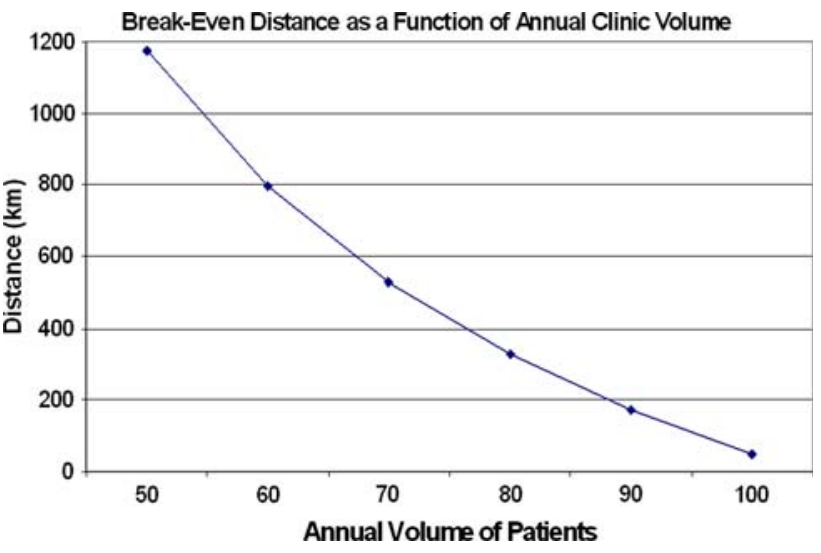

Fig. 2 Break-even travel distance rises exponentially with decreasing annual volumes

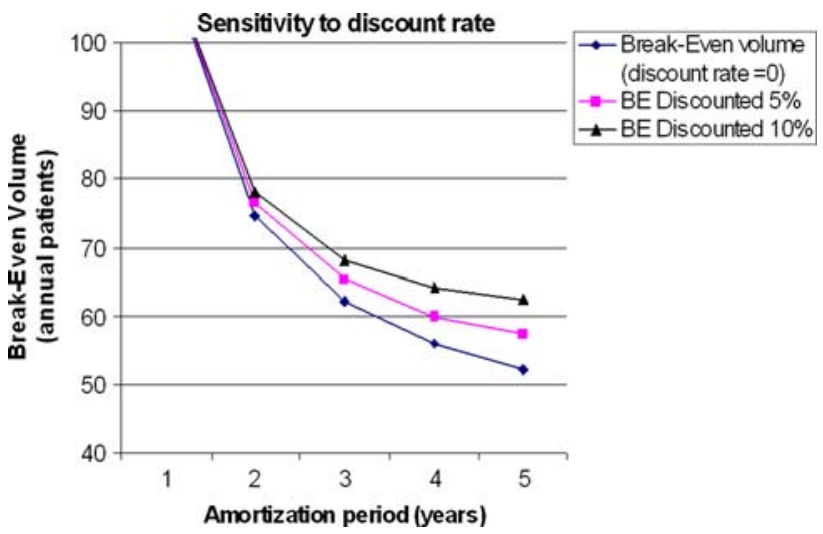

Fig. 3 Sensitivity analysis to discount rate demonstrates limited impact on break-even volume. $B E$ break-even volume

have previously criticized other studies for failing to integrate this measure of risk in their cost modelling. ${ }^{1}$ Telemedicine provided a significant cost advantage under all discount rates utilized. Assuming a discount rate of $10 \%$ resulted in a break-even volume of 65 patients per annum (Fig. 3).

\section{Discussion}

Key findings of this study include a significant cost advantage of TM for patients and attendees as well as attainable break-even patient volumes. These findings infer a clinically significant improvement on a patient's financial burden, a factor which likely contributes to a greater degree of patient satisfaction in the TM group compared with the IP group.

Unlike other studies of TM, which primarily dealt with feasibility assessments, ${ }^{11,12}$ the focus of this randomizedcontrolled trial of TM was on chronic pain, and this study also incorporated discounting and break-even analysis. This 
study has a number of strengths. First, the magnitude of the difference across a broad range of possible discount rates, amortization periods, and mileage allowances made TM appealing. Specifically, the break-even volume remained highly attainable, even under assumptions of high discount rates and short amortization periods. Furthermore, internally valid results were realized due to the randomized twoperiod crossover study design, the clearly defined study population, and the use of standardized assessments both for health-related quality of life (the IIRS) and daily pain scores (as reported by patients). The crossover design minimized the chance for allocation bias and bias resulting from the inherent difficulty of blinding such a study. Finally, this study took the societal perspective in assessing both direct and indirect costs to the patients and the institution. Regardless of payer and beneficiary differences, this approach provided a more complete representation of the impact of this intervention.

There are several limitations which merit consideration. In accordance with financial and budgeting principles, we did not address sunk costs. One important sunk cost, which was not factored into our analysis, is government investment in the Ontario Telemedicine Network. As this money was already invested and is not recoverable, financial models would not generally include this cost. However, this limits the applicability of our findings in other locations which have not already established such a network. Such facilities would need to consider investment costs or variable costs related to procuring network access time. ${ }^{17}$ Likewise, only costs that might potentially diverge between arms were captured. As a result, costs of physician time (among others) were not captured because visits are equally remunerated on a fee-for-service basis regardless of IP or TM status, and the number of follow-up physician visits was similar between both arms.

Another limitation is that this financial analysis hinged on the validity of our assumptions regarding fixed and variable costs. First, we assumed that cost data collected from the patients' diaries were complete and accurate, although we knew that some costs may have been omitted or erroneously recorded. However, this was the most accurate data available for prospective collection, and it best reflected the financial burden on patients. In order to underestimate the benefit of TM consultations, most other assumptions were conservative. Specifically, the cost of the modular unit likely would have decreased over time. Also, our model may have strongly underestimated the impact of rising fuel prices on travel costs, as this was a significant means of cost savings in the TM group. Then again, the actual cost for the TM resource person was difficult to model. A part-time audio-visual technologist could easily be responsible for the daily operation of our unit, and at low cost. However, our institution's desire to develop a program focusing on research and education around this technology requires an individual with a greater range of clinical experience, thereby increasing the annual operating costs. Thus, we modelled the need for higher labour costs in the development year, with a reduced cost for subsequent maintenance of the equipment.

Additionally, there are two reasons why this study represents a cost minimization analysis without providing a cost-benefit evaluation. First, cost-benefit analysis would have introduced uncertainty and error if benefit were converted to a standardized value (e.g., quality- or disabilityadjusted life years). Second, cost-benefit analysis would have been helpful only to determine whether the benefit/ cost ratio reached a minimal threshold to warrant additional expense. However, since TM represents a dominant strategy (better outcome and lower cost) at volumes above break-even value, this step was not necessary.

Finally, the nature of this intervention did not lend itself to a blinded study. Likewise, allocation concealment was not possible when patients knew the nature of the subsequent visit based on their initial encounter. These factors may have coloured patients' perceptions or their reporting of costs and satisfaction. Furthermore, assessors were not blinded, nor were patients who were assessing their own pain scores and calculating costs. However, the crossover design did permit each patient to serve as his or her own control and, therefore, limited the impact of these factors.

One important issue for discussion is the payer-beneficiary gap. In this case, patients enjoyed substantial cost savings and reported a better satisfaction score (a clearly dominant strategy by decision-analysis metrics); however, the hospital was responsible for funding the costs and bearing the logistical burden. Hospital administrators considering TM should consider the portion of their global budget required for this investment and compare this cost with the patient advantages as previously described.

In conclusion, we have shown a significant net economic benefit associated with the use of TM in the follow-up of patients who attended a multidisciplinary pain clinic wherein established methods for analysis of cost-effectiveness were used and new health initiatives were economically valuated. Given the significant capital expense involved in establishing a TM capability, this study outlines the types of local analyses that might be utilized to demonstrate costeffectiveness when considering adoption of this technology. In addition to the cost savings from both patient and societal perspectives, the patients were more satisfied with the TM consultation. Patient-based outcomes did not differ, as this study was unable to discern any difference in subsequent health care appointments or HRQL, as measured by IIRS score. This result is likely due to the small number of patients and the relative insensitivity of the instruments used in this application. Further studies are needed to confirm and extend 
this observation as well as to determine which specific pain patient groups would benefit most from this approach. Hospital administrators considering a capital investment in TM products should consider the significant improvement in patient satisfaction and the economic benefit to patients at a break-even program participation rate of one patient per week.

Acknowledgements We sincerely thank Enza Barbati and Diana Bereti for their administrative expertise in support of this study. This work was supported by a grant from Physican Services Incorporated (PSI).

Conflicts of interest None declared.

\section{References}

1. Roine R, Ohinmaa A, Hailey D. Assessing telemedicine: a systematic review of the literature. CMAJ 2001; 165: 765-71.

2. Currell R, Urquhart $C$, Wainwright $P$, Lewis R. Telemedicine versus face to face patient care: effects on professional practice and health care outcomes. Cochrane Database Syst Rev 2000; (2): CD002098.

3. Appel PR, Bleiberg J, Noiseux J. Self-regulation training for chronic pain: can it be done effectively by telemedicine? Telemed J E Health 2002; 8: 361-8.

4. Statistic Canada. Health Indicators. 82-221-XIE. 2002. http://www. statcan.gc.ca/pub/82-221-x/01002/4061980-eng.htm. Accessed May 2009.

5. Moulin DE, Clark AJ, Speechley M, Morley-Forster PK. Chronic pain in Canada-prevalence, treatment, impact and the role of opioid analgesia. Pain Res Manag 2002; 7: 179-84.

6. Haddox JD, Bonica JJ. Evolution of the specialty of pain medicine and the multidisciplinary approach to pain. In: Cousins MJ, Bridenbaugh PO, editors. Neural Blockade in Clinical Anesthesia and Management of Pain. Philadelphia: Lippincott-Raven; 1998. p. $1113-4$.

7. Ospina $M$, Harstall $C$. Multidisciplinary pain programs for chronic pain: evidence from systematic reviews. Alberta Heritage Foundation for Medical Research; 2003: 1-56

8. Jovey RD, Ennis J, Gardner-Nix J, et al. Use of opioid analgesics for the treatment of chronic noncancer pain-a consensus statement and guidelines from the Canadian Pain Society, 2002. Pain Res Manag 2003; 8(Suppl A): 3A-28A.

9. Peng $P$, Choiniere $M$, Dion D, Intrater $H$, et al. Challenges in accessing multidisciplinary pain treatment facilities in Canada. Can J Anesth 2007; 54: 977-84.

10. Lubeck DP. The costs of musculoskeletal disease: health needs assessment and health economics. Best Pract Res Clin Rheumatol 2003; 17: 529-39.

11. Wan AC, Gul Y, Darzi A. Realtime remote consultation in the outpatient clinic-experience at a teaching hospital. J Telemed Telecare 1999; 5(Suppl 1): S70-1.

12. Glazer HI, Marinoff SC, Sleight IJ. Web-enabled Glazer surface electromyographic protocol for the remote, real-time assessment and rehabilitation of pelvic floor dysfunction in vulvar vestibulitis syndrome. A case report. J Reprod Med 2002; 47: 728-30.

13. Peng PW, Stafford MA, Wong DT, Salenieks ME. Use of telemedicine in chronic pain consultation: a pilot study. Clin J Pain 2006; 22: 350-2.

14. Devins GM, Dion R, Pelletier LG, et al. Structure of lifestyle disruptions in chronic disease: a confirmatory factor analysis of the Illness Intrusiveness Rating Scale. Med Care 2001; 39: 1097104.

15. Wootton R, Bloomer SE, Corbett R, et al. Multicentre randomised control trial comparing real time teledermatology with conventional outpatient dermatological care: societal cost-benefit analysis. BMJ 2000; 320: 1252-6.

16. Vehicle, travel and sales expenses of employees. Income Tax Interpretation Bulletin. Canada Revenue Agency. http://www. cra-arc.gc.ca/E/pub/tp/it522r/it522r-e.html\#allowance. Accessed Sept 11, 2008.

17. Telemedicine: fad or future? (Editorial). Lancet 1995; 345: 73-4. 